Jozef Melcer - Jan Kortis - Lubos Daniel - Peter Fabo*

\title{
IDENTIFICATION OF MODAL FREQUENCIES FROM THE PRE-STRESSED CONCRETE BRIDGE DYNAMIC RESPONSE TO DIFFERENT SOURCES OF DYNAMIC EXCITATION
}

\begin{abstract}
The natural frequencies and mode shapes are unique characteristics of each mechanical structure. Their prediction is a crucial part of each dynamic experimental measurement. However, the proper identification of higher natural frequencies and mode shapes can be a problem, especially for big structures such as bridges. The reason is the need to excite the bridge in such a way that it responds in a free-vibrations mode shape. This paper describes three various sources of excitations, which are used to identify the modal characteristics of the pre-stressed concrete bridge. The impulse excitation, traffic load and ambient vibration are used and analyzed. In the case of the loading by a force impulse, modal shapes are also obtained. The study shows that the intensity and kind of the excitation has a noticeable impact on identification of modal frequencies. Finally, the results of the experimental measurements are used to calibrate the numerical model.
\end{abstract}

Keywords: dynamic excitation, modal frequencies, free vibrations, moving load, FRF function

\section{Introduction}

There is a long tradition in the Czech and Slovak Republic to investigate the effect of moving load on the bridge structures [1], [2]. The theoretical approaches have been also supported with the experimental investigation [3], [4]. The dynamic experimental measurements of real bridge structures are an important source of data that can be used in different ways. Detection of modal characteristics is one of the most important [5]. Knowledge of them is an essential assumption for various applications like model updating, dynamic load identification and health monitoring, or a damage detection problem. There seems to be important to make the right decision on which suitable excitation technique should be used with respect to the conditions that are unique for each bridge structure. From a practical point of view, diagnostic methods, like operational modal analysis (OMA), are preferred because no excitation devices are used and the traffic on the bridge is not limited [6]. Even though that these techniques are useful, it is not clear if they are useful for all conditions.

The main issue in this case is to apply various excitation sources and to analyze effect of them on the obtained modal frequencies of the bridge. The first source of excitation is the impact device, which loads the bridge with an impact impulse (impulse load) in the selected points. In this case, the intensity of impulse is also measured so the techniques of experimental modal analysis (EMA) are used to obtain the modal shapes and frequencies. The second source of excitation is a heavy vehicle passing over the bridge. In that case, the measured dynamic properties of the system vary over time as the vehicle changes its position on the bridge. The advantage is that the weight and position of the vehicle during the measurements are well-known. The ambient vibrations, caused by a train passing over the rail located under the bridge, is the third source of the excitation [7]. This kind of load can be defined as purely random ambient excitation. The speed and weight of the train are not clearly known, as they were not investigated.

The same methodology of transformation of the obtained measured signals into the frequency-domain is chosen for all the three cases (sampling frequencies, filtering, time window, etc.). In the cases when the bridge is excited by an impact device and by the passing train, the frequency response functions (FRF) were also calculated by applying the techniques of OMA and EMA. The article also presents the application of measured data to verify the numerical model of the bridge.

The presented study is focused on the road bridge situated between the two villages, Varin and Mojs, near the city Zilina in the Slovak Republic (Figure 1a). The full length of three span bridge is $87 \mathrm{~m}$. Each span acts independently as a simple supported beam. The main girders 25 I-73 are prefabricated prestressed concrete structures with the length $29 \mathrm{~m}$. The girders are placed in the transversal position with the mutual distance 1.44$1.45 \mathrm{~m}$. The cross-section of the bridge contains eight girders. The shapes of the girders and the layers of pavement are showed in the Figure 1b.

\section{The excitation of the bridge with impact load}

The impulse load is used for experimental modal analysis (EMA) of the bridge. The EMA is a common technique that is used to obtain the frequency response function. Consequently, the modal frequencies and mode shapes of the structure are estimated [8]. The hammer impulse excitation device or electrodynamic shaker are often used as a source of excitation. The choice depends

\footnotetext{
* ${ }^{1}$ Jozef Melcer, ${ }^{2}$ Jan Kortis, ${ }^{2}$ Lubos Daniel, ${ }^{2}$ Peter Fabo

${ }^{1}$ Department of Structural Mechanics and Applied Mathematics, Faculty of Civil Engineering, University of Zilina, Slovakia

${ }^{2}$ Research Center, University of Zilina, Slovakia

E-mail: jan.kortis@fstav.uniza.sk
} 


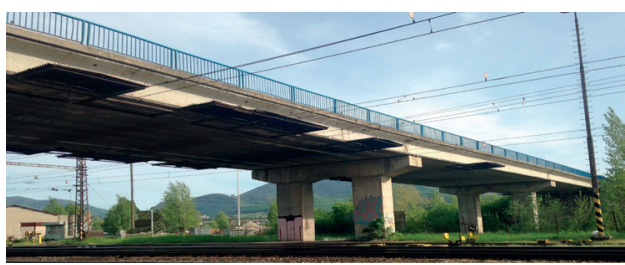

$a$

Figure 1 Measured and analyzed concrete bridge, $a$ - photography of actual state, $b$ - the draw of the cross-section

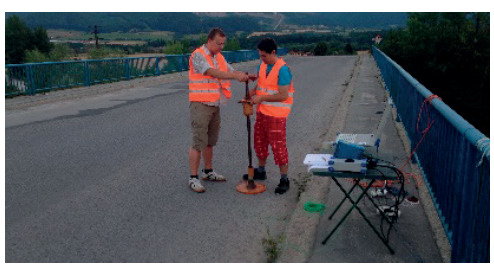

$a$

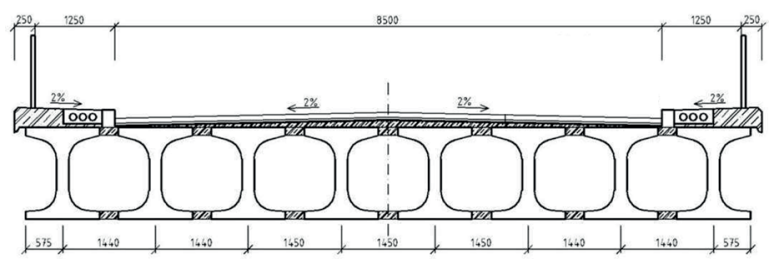

$b$

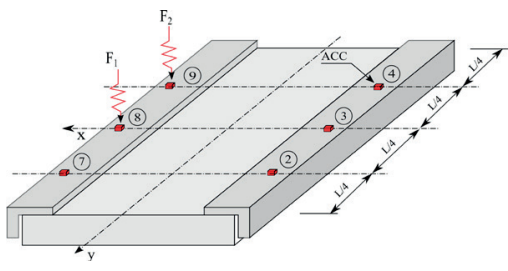

$b$

Figure 2 Modal analysis of the bridge excited by the impact load, a-impact device and its application, $b$ - location of the measurement and loading points

on the type of structure and what is required to be obtained. In the presented case, the bridge is excited with the impact device with mass that has weight $10 \mathrm{~kg}$ and it falls from $1.0 \mathrm{~m}$ height (Figure 2a). The sensor that measures the dynamic force is positioned in the contact steel plate. It is a piezoelectric force transducer Kistler 906. The response of the bridge is measured with six piezoelectric accelerometers BK 4508 B002. The analogue signals from the accelerometers and force transducers are amplified and digitalized with the device DEWETRON DEWE-3200.

The location of the accelerometers (ACC) on the bridge and the positions of the excitation points $\left(\mathrm{F}_{1}, \mathrm{~F}_{2}\right)$ are shown in Figure $2 \mathrm{~b}$. The points are situated in the middle and in the quarter of the span, transversally; they are situated on the edge of the pavement. There were seven force impulses generated with the impact device during one measurement. An example of the time series of the measured excitation (impulse at the point $\mathrm{F}_{1}$ ) and the bridge response (accelerometer in the point $\mathrm{ACC}_{2}$ ) are shown in Figure 3.

Six frequency response functions (FRF) are obtained. The last step is to average them and to obtain a Modal Identification Function (MIF). Figure 4 shows results of the modal analysis for impulse load located at point $F_{1}$ (Figure $4 a$ ) and at point $F_{2}$ (Figure 4b).

The first bending mode shape on the frequency $\mathrm{f}_{1}=3.906 \mathrm{~Hz}$ and the first torsional mode shape on the frequency $\mathrm{f}_{2}=7.813 \mathrm{~Hz}$ were identified in the MIF for point $F_{1}$. The second bending mode shape on the frequency $\mathrm{f}_{3}=14.453 \mathrm{~Hz}$ and the second torsional mode shape on the frequency $\mathrm{f}_{4}=19.953 \mathrm{~Hz}$ were identified in the MIF for point $F_{2}$. The higher mode shapes were not possible to identify correctly, as there was not sufficient number of measurements points. One of the alternatives, for the same number of accelerometers, seems to be an approach when the measurement is repeated for various locations of measurements points. This has not been applied here.

\section{The excitation of the bridge with the moving lorry}

The moving lorry T-815 was the second source of excitation. This type of excitation is recommended in the Slovak technical
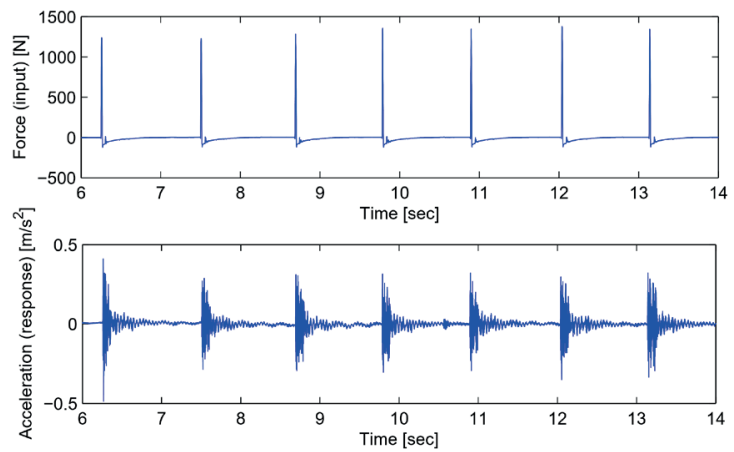

Figure 3 Example of the measured input (impulse $F_{l}$ ) and output signals $\left(A C C_{2}\right)$

standard STN 736209 for the dynamic diagnostic tests of the bridges with longer span than $40 \mathrm{~m}$. The obstacle in the middle of the span was used to increase the excitation with the vehicle. The dynamic response of the bridge was measured with the piezoelectric accelerometers BK 8306 (BK1, BK2) located in the middle and quarter of the span. In this case, it is necessary to identify the moment when the vehicle arrives and leaves the bridge. For that purpose, the steel plates with accelerometers BK 4508B 002 (AC1, AC2) are located on the pavement at the beginning and at the end of the span. The situation on the bridge and the positions of the sensors are shown in Figure 5.

During the measurement, 21 passes of the vehicle at different speeds from 5 to $35 \mathrm{~km} / \mathrm{h}$ were performed with a gross weight of a vehicle of $22.9 \mathrm{t}$ (rear axle $17.45 \mathrm{t}$, front axle $5.45 \mathrm{t}$ ). In Figure 6 there are also results of the FFT that were obtained for the measured signal from accelerometers BK1 and BK2. The function is divided into three parts $\left(t_{1}\right.$ - before the beginning of the test, $t_{2}$ - forced vibrations, $t_{3}$ - free vibrations). From the measured data, the first two significant frequencies were obtained; the first measured frequency $\mathrm{f}_{1}=3.91 \mathrm{~Hz}$ corresponding to the first bending mode shape and the second frequency $\mathrm{f}_{2}=7.81 \mathrm{~Hz}$ corresponding to the first torsional mode shape.

The results show that the changes in the modal frequencies, while the vehicle is on the bridge, do not vary significantly for the investigated structure. From the free vibrations $\left(t_{3}\right)$ of the 

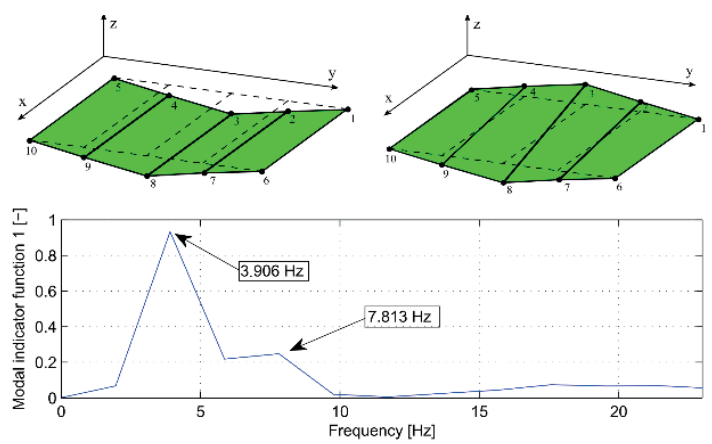
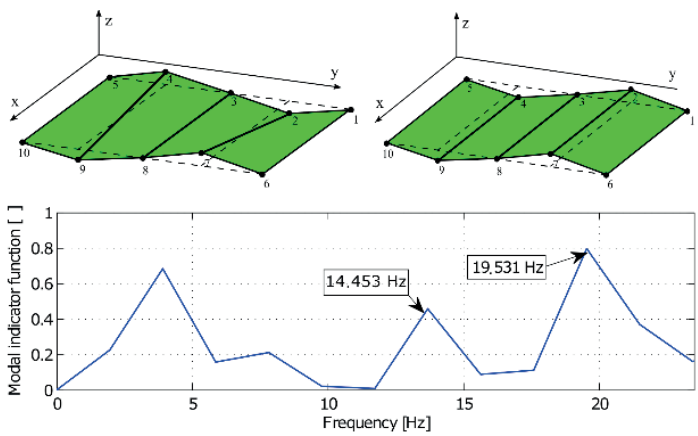

Figure 4 MIF functions and modal shapes of the bridge, a-analysis from impact $F_{l}, b$-analysis from impact $F_{2}$

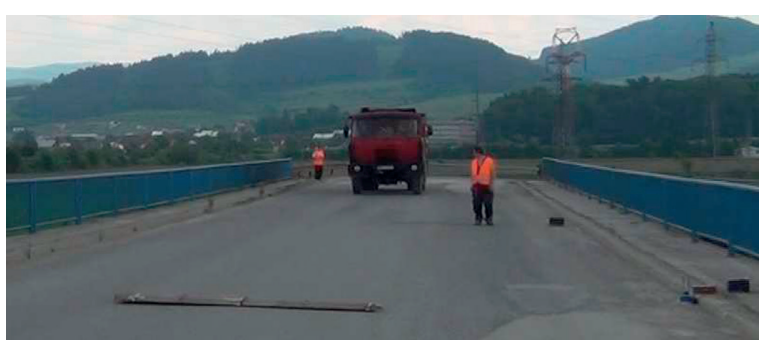

$a$

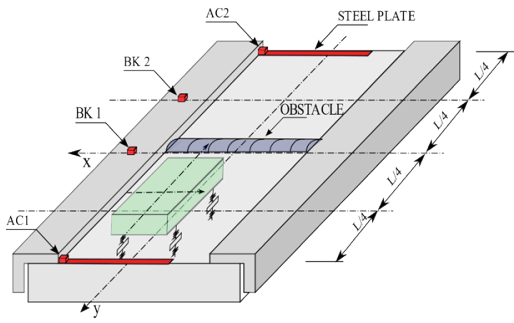

$b$

Figure 5 Situation on the bridge by the dynamic measurement, $a$-situation on the bridge and lorry, $b$-positions of the sensors
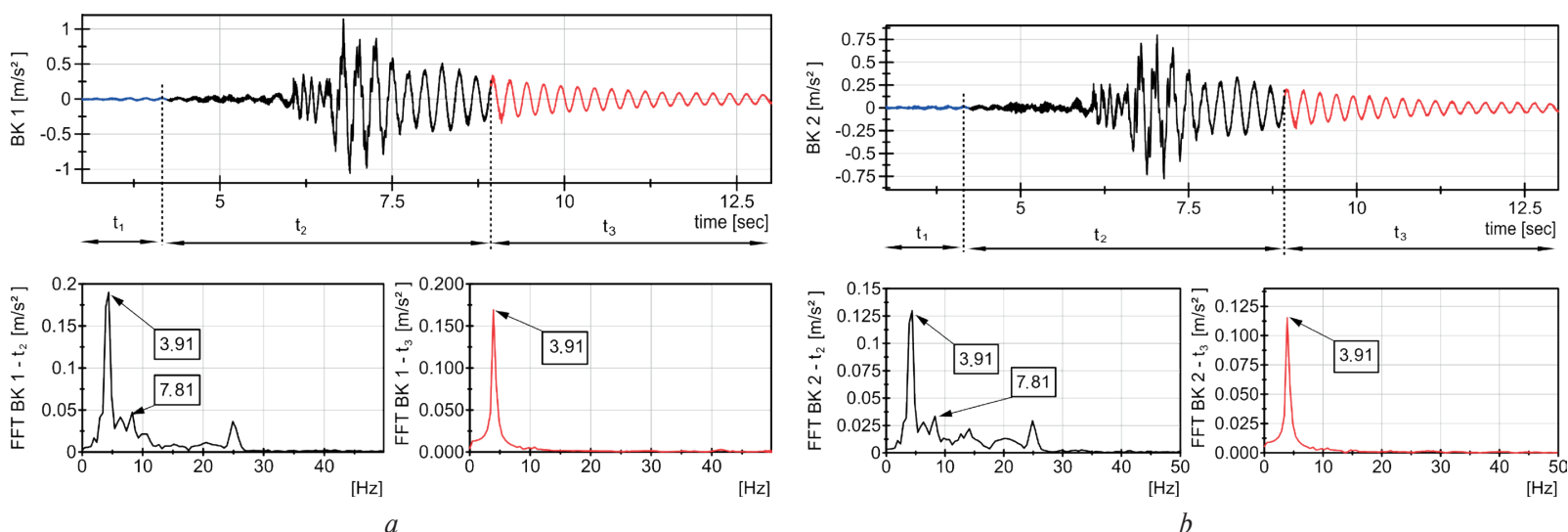

Figure 6 The measured signals and spectrums from accelerometers BK1 (a), BK2 (b)

structure, it was not possible to recognize the higher mode shapes (frequencies). The reason is the effect of structural damping on the higher mode shapes.

\section{The excitation of the bridge with the train moving on the railway near the bridge (ambient vibrations)}

The last source of the excitation were the ambient vibrations, generated by the moving train. It was a common passenger train moving at the speed of $80-90 \mathrm{~km} / \mathrm{h}$ on the rail road, which is crossed under the bridge. The natural bridge frequencies were recognized from the FRF functions that were derived from the response signals and the input signals. The input signal at the ground near to the pillar was measured with the accelerometer BK 8306 (ACC1). The response of the bridge was measured by the two accelerometers BK 8306 positioned in the middle of the span (ACC3) and in the one fourth of the span (ACC2). The whole situation during the experimental measurement is shown in Figure 7.

The example of the measured input (ACC1) and output signals $(\mathrm{ACC} 2, \mathrm{ACC} 3)$ are shown in Figure $7 \mathrm{c}$. In the FRF functions, the three modal frequencies are identified (Figure 8). Modal frequencies $\mathrm{f}_{1}=3.906 \mathrm{~Hz}$ and $\mathrm{f}_{3}=14.650 \mathrm{~Hz}$ are also identified in previous measurements. The peak at the frequency $\mathrm{f}_{2}=9.280 \mathrm{~Hz}$, which is identified in both FRF signals is very interesting as it was not possible to identify it in the previous cases. The following comparison to the numerical model shows that it is also a natural frequency.

\section{Calibration of the numerical model of the bridge based on the FEM}

The last part in the article is focused on application of the obtained data from the experimental analysis for calibration of the numerical model of the concrete bridge. A model of the whole 


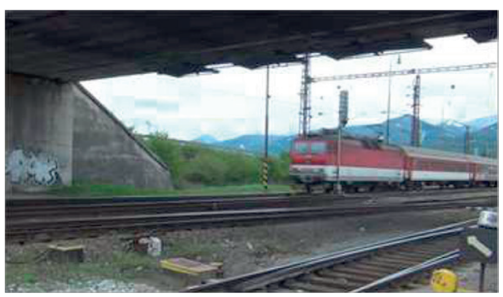

$a$

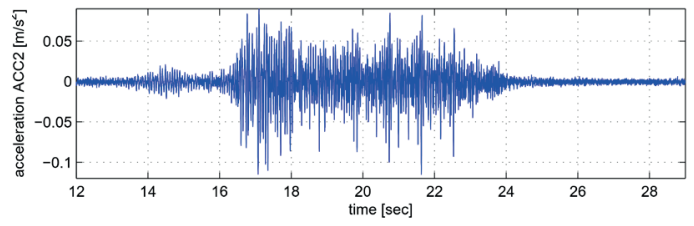

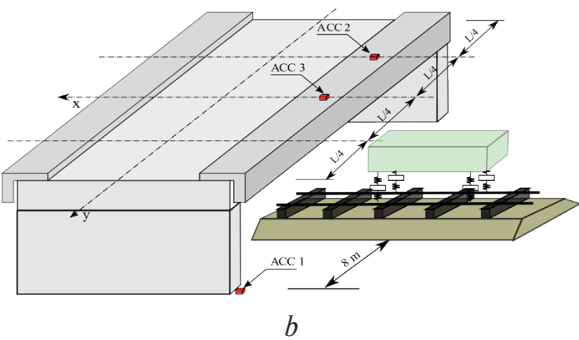

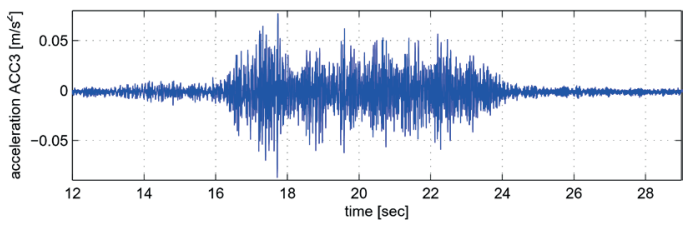

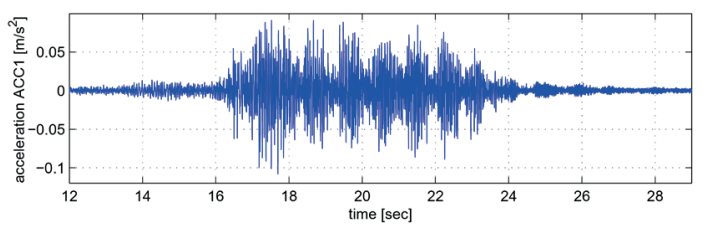

$c$

Figure 7 Ambient vibration of the bridge generated by the mobbing train, $a$-passing train, $b$-positions of the sensors, $c$ - example of the signals

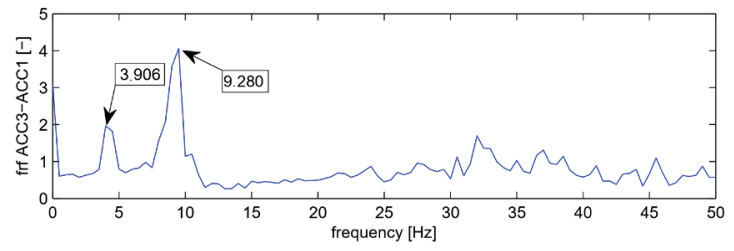

a

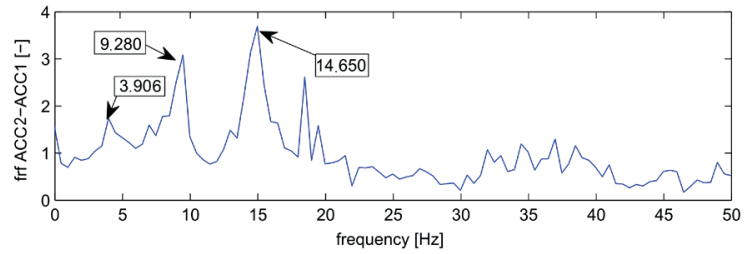

b

Figure 8 FRF functions of the structure between sensors ACC3-ACC1 (a), ACC2-ACC1 (b)

Table 1 The material characteristics of the structure parts of the bridge

\begin{tabular}{cccc}
\hline Construction part & Young modulus [GPa] & Poisson's ratio [-] & Density [kg/m3] \\
\hline Main girders I & 42 & 0.15 & 2600 \\
Concrete bridge deck & 28 & 0.25 & 2400 \\
Concrete cornice & 31 & 0.3 & 2300 \\
Concrete fills & 2 & 0.3 & 2300 \\
\hline
\end{tabular}

bridge was not created, but only a model of the middle span. That is enough since the measurements show that each span acts as a single supported beam. The 3D model (3D solid elements) in the commercial software ADINA 9.1 was created, which uses the finite element method for the mathematical definition of the mechanical structures. The numerical model was divided into fourth parts; each part has different linear isotropic material characteristics with respect of the material defined in the plans and technical reports of the bridge values and they are defined in Table 1.

There was only a problem to choose the right characteristics of the concrete fills used between the girders. Their material properties have a significant effect on the global torsional stiffness of the structure and they influence all the calculated modal shapes. Their characteristics were possible to be updated only after the experimental analysis. For surfaces, where girders are placed on bearings, the boundary conditions were defined. The zero translation for the vertical directions and for horizontal direction were defined where there are bearings with restrictions. The geometry of the model with different color for each structural part is shown in Figure 9. The continuous connection of the mesh was created between the elements with different material parameters.

The natural frequencies and mode shapes are computed by application of the Lanczos algorithm. Five natural frequencies and mode shapes were calculated. Figure 10 shows two bending shapes corresponding to the frequencies $\mathrm{f}_{1}=3.899 \mathrm{~Hz}$ and $\mathrm{f}_{4}=$ $14.510 \mathrm{~Hz}$, two torsional shapes corresponding to frequencies $\mathrm{f}_{2}=7.856 \mathrm{~Hz}$ and $\mathrm{f}_{5}=20.210 \mathrm{~Hz}$ and bending-torsional shape corresponding to the frequency $\mathrm{f}_{3}=9.281 \mathrm{~Hz}$.

Summary of the calculated natural frequencies and the frequencies obtained from the experimental analysis are 


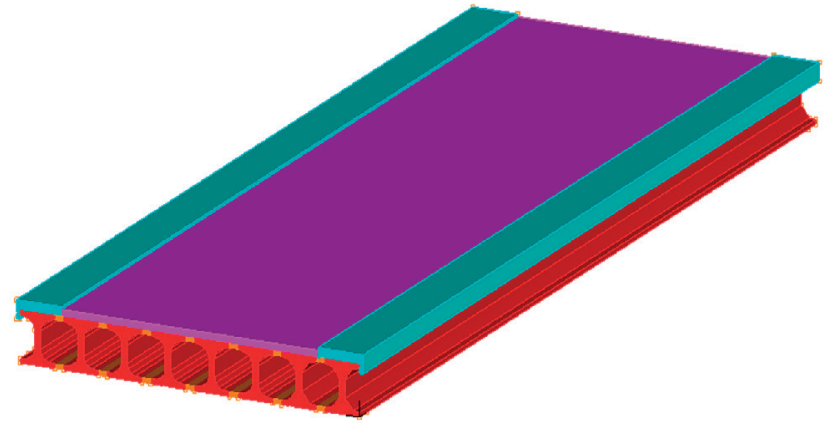

Figure 9 The 3D FEM model of the bridge in the software ADINA

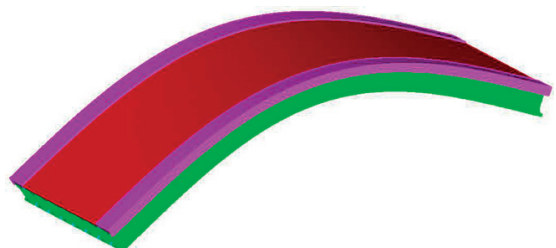

$f 1=3.899 \mathrm{~Hz}$

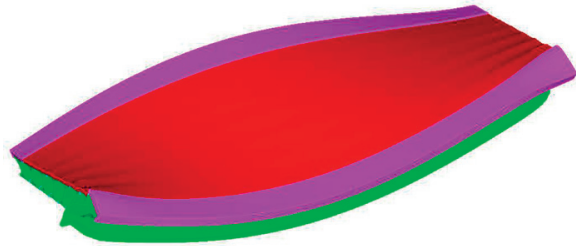

$f_{3}=9.281 \mathrm{~Hz}$

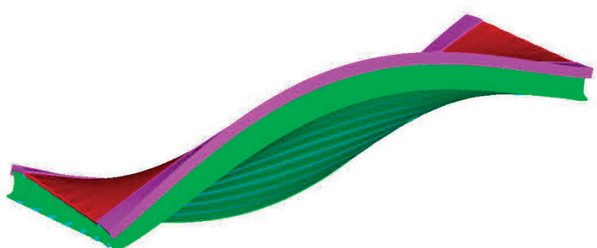

$f_{2}=7.856 \mathrm{~Hz}$

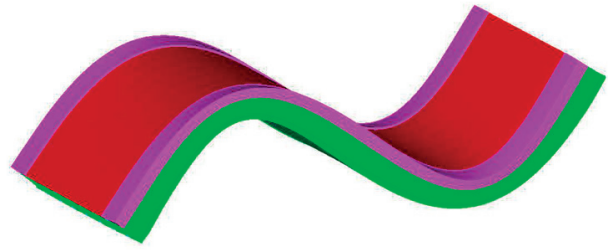

$f_{4}=14.510 \mathrm{~Hz}$

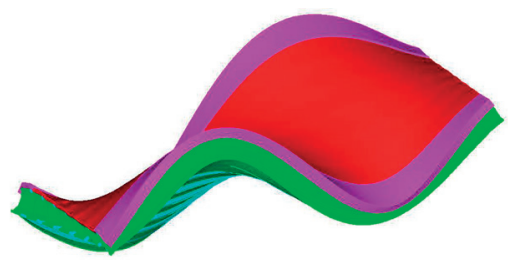

$f_{5}=20.210 \mathrm{~Hz}$

Figure 10 Modal shapes of the 3D model of the bridge

Table 2 Summary of the natural frequencies

\begin{tabular}{|c|c|c|c|c|}
\hline \multirow{3}{*}{ Modal shapes [-] } & \multicolumn{4}{|c|}{ Identified modal frequencies $\mathrm{f}_{\mathrm{i}}[\mathrm{Hz}]$} \\
\hline & \multirow{2}{*}{ FEM model } & \multicolumn{3}{|c|}{ Experimental measurements } \\
\hline & & Impulse force & Moving vehicle & Ambient vibration \\
\hline 1. Bending mode & 3.899 & 3.906 & 3.910 & 3.906 \\
\hline 2. Torsional mode & 7.856 & 7.813 & 7.810 & Indeterminate \\
\hline 3. Torsional-bending mode & 9.281 & Indeterminate & Indeterminate & 9.280 \\
\hline 4. Bending mode & 14.510 & 13.687 & Indeterminate & 14.650 \\
\hline 5. Torsional mode & 20.210 & 19.531 & Indeterminate & Indeterminate \\
\hline
\end{tabular}

shown in the Table 2. The results show that all the calculated modal frequencies of the structure are also recognized by the experimental measurements. The frequency of $9.280 \mathrm{~Hz}$ is interesting. This frequency was obtained in the model only when the Young modulus of the concrete fills between the girders was changed to the value $2 \mathrm{GPa}$ (Table 1 ). After the torsional stiffness of the cross-section is reduced, the calculated natural frequencies were reduced to the values comparable to the natural frequencies obtained from the measurements. The second and fourth natural frequencies of the numerical model, after Young modulus of concrete fills was updated, were comparable to the measured frequencies.

The sources of excitation with impulse force and with moving vehicle primarily excited the first torsional mode shape at frequency $\mathrm{f}_{2}=7.856 \mathrm{~Hz}$. This frequency is very close to the third one $\mathrm{f}_{3}=9.281 \mathrm{~Hz}$, so the dominant second frequency covers the 
third natural frequency. It was possible to be identified only when the structure was excited by the ambient vibrations. As a result, the third natural frequency was not possible to be identified if the bridge was excited by the vertical loading. On the other hand, the first torsional mode shape was not possible to be identified correctly from the response of the bridge to the excitation by the train.

\section{Conclusions}

The dynamic properties of the concrete bridge were measured and investigated by applying the various types of the excitations. The presented results show that different sources of excitations can lead to identification of different natural frequencies of the structure. For instance, the third torsional-bending mode shape of the investigated bridge can be excited and its frequency can be identified only when the bridge is excited by the ambient vibrations. On the other hand, the first torsional mode shape is excited only by the vertical load, like the impact force or the moving vehicle. In that case, the results of numerical model were crucial to identify the natural frequencies correctly. The combination of measurements of the response to several types of excitations with the results of numerical model seems to be a suitable alternative for proper identification of all the modal characteristics.

\section{Acknowledgments}

This paper was supported by the Grant Research Cetnre of The University of Zilina - Second Phase (grant No. 313011D011) and by the Grant National Agency VEGA of the Slovak Republic (grant No. 1/005/16).

\section{References}

[1] KOLOUSEK, V., MCLEAN, R. F.: Dynamics in Engineering Structures. Butterworths, 1973.

[2] FRYBA, L.: Vibration of Solids and Structures under Moving Loads. Springer Science \& Business Media, 2013.

[3] FISCHER, O., PIRNER, M.: Modal Analysis and Analysis of Forced Vibrations of Multispan Bridges. Acta technica CSAV, 50(2), 167-176, 2005.

[4] FRYBA, L., PIRNER, M.: Load Tests and Modal Analysis of Bridges. Engineering Structures, 23(1), 102-109, 2001. https://doi. org/10.1016/S0141-0296(00)00026-2

[5] TESAR, A., MELCER, J.: Structural Monitoring in Advanced Bridge Engineering. International Journal for Numerical Methods in Engineering, 74(11), 1670-1678, 2008. https://doi.org/10.1002/nme.2224

[6] KORTIS, J., DANIEL, L., FARBAK, M., MALIAR, L., ŠKARUPA, M.: Operational Modal Analysis of the Cable stayed Footbridge. Civil and Environmental Engineering, 13(2), 92-98, 2017. https://doi.org/10.1515/cee-2017-0012

[7] KOUROUSSIS, G., CONNOLly, D. P., VERLINDEN, O.: Railway-Induced Ground Vibrations - A Review of Vehicle Effects. International Journal of Rail Transportation, 2(2), 69-110, 2014. https://doi.org/10.1080/23248378.2014.897791

[8] CUNHA, A., CAETANO, E.: Experimental Modal Analysis of Civil Engineering Structures. Sound \& Vibration, 40(6), $12-20,2006$. 